\title{
Evaluation of Biventricular Function by Cadmium- zinc-telluride SPECT Gated Tomographic Radionuclide Angiography: Comparison to Conventional SPECT
}

\author{
Yue Chen \\ TEDA International Cardiovascular Hospital \\ Zekun Pang \\ TEDA International Cardiovascular Hospital \\ Jiao Wang \\ TEDA International Cardiovascular Hospital \\ Jianming Li ( $D$ ichlijm@163.com )
}

TEDA International Cardiovascular Hospital https://orcid.org/0000-0002-2585-4753

\section{Research Article}

Keywords: cadmium-zinc-telluride, CZT, single photon emission tomography, SPECT, multi-gated acquisition, MUGA, biventricular function, repeatability

Posted Date: August 24th, 2021

DOI: https://doi.org/10.21203/rs.3.rs-822152/v1

License: (c) (i) This work is licensed under a Creative Commons Attribution 4.0 International License.

Read Full License 


\section{Abstract}

To compare and analyze the consistency and repeatability of left ventricular (LV) and right ventricular (RV) functions obtained by radionuclide multi-gated acquisition (MUGA) with cadmium-zinc-telluride SPECT (CZT-SPECT) and conventional SPECT(C-SPECT) with sodium iodide (Nal) crystal detectors. Seventy-seven patients who underwent C-SPECT planar MUGA and CZT-SPECT tomographic MUGA on the same day were respectively enrolled and reviewed. Comparing the correlation and difference of LVEF, RVEF, PER, and PFR between the two cameras, The repeatability of the left and right ventricular function parameters obtained by the two cameras was also compared. There was a good correlation $(R=0.831, P$ $<0.001)$ of LVEF obtained by the two cameras, the comparison of RVEF $(r=0.619, P \otimes 0.001)$, LVPER $(r=0.672, P \otimes 0.001)$ and LVPFR $(r=0.700, P \otimes 0.001)$ showed a modest correlation and the comparison of RVPER $(r=0.463, P \llbracket 0.001)$, LVPFR $(r=0.253, P \unrhd 0.05)$ showed a poor correlation. In terms of repeatability, the intraclass correlation coefficient (ICC) of RVPFR(P) was good $(0.698, P \unrhd 0.001)$, while the ICC in other groups was excellent $(0.823 \sim 0.989, \mathrm{P} \otimes 0.001)$. The repeatability of LVEF and RVEF measured by CZTSPECT was better than C-SPECT. The repeatability of LVEF and PER measured by two cameras was better than their respective RVER and PFR. The repeatability of PER and PFR of LV was better than RV for both cameras. CZT-SPECT tomographic MUGA had a good correlation with C-SPECT cardiac planar MUGA in evaluating left and right ventricular systolic function and left ventricular diastolic function, and the repeatability above was even better. The determination of right ventricular diastolic function still needed further study. MUGA with CZT-SPECT will play an important and unique role in the clinical application of accurate evaluation of biventricular function in the future.

\section{Introduction}

Radionuclide angiography can non-invasively reflect left and right ventricular ejection fraction, ventricular systolic(and diastolic) volume, systolic phase, peak ejection (and filling) rate, and wall motion, etc., which are of great value in cardiac function evaluation, cardiac conduction and auxiliary diagnosis of cardiomyopathy of coronary artery disease (CAD). It also has essential monitoring value for noncardiovascular diseases, especially the cardiac toxic and side effects of chemotherapy and targeted therapy for cancer patients [1-2]. In addition, the evaluation of left and right ventricular mechanical contraction synchronization has been paid great attention in clinical practice[3-4]. In the early stage, planar multi-gated acquisition(MUGA) was the most classic method, but the accuracy of ventricular function measurement could be affected by the overlap of atrium and ventricle, background delineation, and low-counting, especially the accuracy of ventricular volume measurement[5-6]. Tomographic imaging technology overcomes these problems and has good consistency and correlation with cardiac magnetic resonance (CMR) results in left ventricular ejection fraction(LVEF) and volume[7-8]. Especially in patients with left ventricular-assisted device implantation (CMR contraindication), it becomes the first alternative examination[9]. However, the resolution of temporal, spatial and energy, and the sensitivity of counting are always tricky problems that restrict the efficiency of nuclear medicine imaging. In addition, $3 \mathrm{D}$ imaging technology and post-processing analysis must rely on the higher-performance hardware 
support. Cadmium-zinc-telluride SPECT(CZT-SPECT) has greatly improved the above performance and overcame those shortcomings[10], and it is easy to realize low-dose tomography with a high frame number per heart cycle, which significantly improves the acquisition performance of MUGA[11-12]. Although by being limited to the popularity of equipment and technology in recent years, there are few studies on CZT-SPECT tomographic MUGA, the existing studies on its diagnostic efficiency and acquisition scheme optimization showed that this technique has great potential application value in the clinic[13-14].

The purpose of this study aims to compare CZT-SPECT tomographic MUGA with Nal-crystal conventional SPECT (C-SPECT) planar MUGA in the consistency of ejection fraction (EF), peak ejection rate (PER), and peak filling rate (PFR) of left/right ventricular (LV/RV), and compare the repeatability difference between observers of the above functional parameters measured by the two cameras, respectively. In addition to this, the repeatability of CZT-SPECT tomography will also be compared and analyzed in measuring enddiastolic volume (EDV), end-systolic volume (ESV), and stroke volume (SV) of LV and RV in order to explore the clinical application value of CZT-SPECT tomographic MUGA.

\section{Materials And Methods}

\section{Study population}

Seventy-seven patients who underwent MUGA from June 2018 to February 2021 were studied. Inclusion criteria: the age was between 18 and 90 years old with suspected or known coronary artery disease(CAD) or other cardiomyopathy, who can tolerate and agree with this examination. Exclusion criteria included patients who were unrecognized by cameras with severe arrhythmia (severe atrial fibrillation, frequent ventricular premature beat, etc.), patients who failed to complete planar and/or tomographic imaging on the same day, and patients who underwent cardiac re-synchronization therapy. The data of 90 patients were retrospectively included and analyzed, and 13 patients were finally excluded(10 of them failed to complete CZT-SPECT tomography after completing C-SPECT planar imaging for personal reasons, and the other 3 patients were unable to obtain the functional parameters accurately due to poor image quality by causes of low labeling rate or poor cardiac function). Seventy-seven patients (49 males and 28 females) were finally enrolled in this study. All patients underwent C-SPECT planar imaging first and then CZT-SPECT tomographic imaging on the same day. Two experienced nuclear medicine physicians reviewed the data, analyzed the collected data on two cameras, and made a blind analysis (Fig. 1). The characteristics of the patients were shown in Table 1. All patients were given informed consent, and the study was in accordance with the Declaration of Helsinki.

\section{Acquisition of C-SPECT and CZT-SPECT imaging}

The injected imaging agents were $99 \mathrm{~m}$-Technetium (99mTc) labeled autologous red blood cells (RBC) in vivo according to the routine method. The dose of radioactivity was about $740-925 \mathrm{MBq}$ for each patient. 
About 15-20min after injections, the patients lay on the couch of the C-SPECT(DiscoveryNM630, GE Healthcare, Milwaukee, WI, USA) in the supine position, and one of the detectors was rotated to the left anterior-oblique position of $45^{\circ}$ and then slightly adjusted to the angle where the left and right ventricles were obviously separated. Then, the planar acquisition by the ECG gated-equilibrium method was performed. The acquisition matrix was $64 \times 64$. The energy window was $\pm 15 \%$, and the energy peak was set at $140 \mathrm{keV}$. The R-R interval was divided into 16 equal parts, and the heart rate window was $\pm 15 \%$. The total acquisition time was 15 minutes or 6 million counts were collected. Immediately after acquisition completion, the patients were transferred to CZT-SPECT(DiscoveryNM530c, GE Healthcare, Milwaukee, WI, USA) scan room, and the detectors were closely attached to the patient's left chest. After automatic recognition of cardiac blood pool shadow, the focal point was set in the center of the left ventricular cavity to start tomographic imaging. The energy window was $\pm 15 \%$, and the energy peak was $140 \mathrm{keV}$. The acceptance of heart rate window and division of R-R interval were the same with C-SPECT. Reconstruction algorithm and filtering were generic. Matrix size was $74 \times 74$ resized to $64 \times 64$. The acquisition time was 10 minutes.

\section{Imaging analysis}

Data processing and recording were carried out at GE 4DR Xeleris Workstation, the planar imaging data were analyzed by EF analysis software(GE Healthcare, Milwaukee, WI, USA), and the tomographic imaging data were analyzed by Cedars-Sinai G-BPGs software(Version2019, Cedars-Sinai, Ca, USA ).

\section{Statistical analysis}

All data were processed using IBM SPSS 26.0. The normal distribution was represented by $\pm \mathrm{s}$, paired ttest and Pearson correlation analysis were used; non-normal distribution was expressed by $M(P 25, P 75)$, and Wilcoxon signed-rank test and Spearman correlation analysis were used. Intraclass correlation coefficient (ICC) was used to evaluate the repeatability of operation among observers, Bland-Altman consistency analysis was added to each matched sample.

\section{Results}

\section{Comparison of LVEF and RVEF}

The functional parameters obtained by C-SPECT planar imaging were abbreviated with suffix $(P)$ (abbreviation of planar), and the functional parameters obtained by CZT-SPECT tomographic imaging were also abbreviated with suffix $(T)$ (abbreviation of tomography) to distinguish them from each other. As shown in Table 2, Figs. 2a and 2c, the LVEF obtained by the two methods for the two cameras are $\operatorname{LVEF}(P)=37.8 \pm 13.0 \%$ and $\operatorname{LVEF}(T)=35 \%(24 \%, 48 \%)$, and there was no significant difference between them $(Z=-1.162, P \llbracket 0.05)$ and the correlation was excellent $(r=0.831, P \llbracket 0.001)$.

The RVEF obtained by the two cameras were RVEF $(P)=40.6 \pm 10.8 \%$ and RVEF $(T)=43.7 \pm 11.4 \%$, respectively. There was a significant difference between them $(T=-2.772, P \llbracket 0.05)$, and the correlation was good $(r=0.619, P \llbracket 0.001)$. Bland-Altman consistency analysis (Fig. 2b, 2d) showed that the $95 \%$ 
confidence intervals of LVEF and RVEF difference between them were $(-16.672 \sim 15.472)$ and $(-15.912 \sim$ 22.112), and the out-of-range ratios were $5.2 \%(4 / 77)$ and $6.5 \%$ (5/77), respectively.

\section{Comparison of LVPER, LVPFR, RVPER, and RVPFR}

LVPFR(T) of 8 patients and RVPFR(T) of 5 patients could not be calculated due to failed recognition of the software, which was not included in the analysis. As shown in Table 3 and Fig. 3, the statistic results obtained by the two methods for the two cameras were as following: LVPER $(P)=1.90 \pm 0.66$ VS. LVPER $(T)=1.81 \pm 0.76$, respectively, with no significant statistic difference $(T=1.353, P \llbracket 0.05)$ and good correlation $(r=0.672, P \otimes 0.001)$ between them. $\operatorname{LVPFR}(P)=1.45(1.05,1.89)$ and $\operatorname{LVPFR}(T)=1.43 \pm 0.62$, respectively, with no significant difference between them $(Z=-1.641, P \bowtie 0.05)$ and the correlation was good $(r=0.700, P 囚 0.001)$.

The RVPER obtained by the two methods for the two cameras were RVPER $(P)=2.07 \pm 0.70$ and RVPER $(T)=2.19 \pm 0.79$, respectively, and there was no significant difference between them $(T=-1.374, P \llbracket 0.05)$, but the correlation was general $(r=0.463, P<0.001)$. RVPFR $(P)=1.38(1.13,1.79)$ and $\operatorname{RVPFR}(T)=1.65$ $(1.35,1.99)$, respectively, with statistical significance $(Z=-3.321, P<0.001)$ and poor correlation $(r=0.253$, $\mathrm{P} \otimes 0.05)$ between them.

Bland-Altman consistency analysis showed the 95\% confidence intervals of the differences in LVPER, LVPFR, RVPER, and RVPFR were [-1.2268 1.0468], [-1.0016 0.8016], [-1.3892 1.6292] and [-1.0144 $1.4944]$, and the out-of-range ratios were $6.5 \%(5 / 77), 7.2 \% \varangle 5 / 69 \rrbracket, 6.5 \% \varangle 5 / 77 \rrbracket$ and $5.6 \% \varangle 4 / 72 \rrbracket$, respectively.

As the comparison results of PER and PFR of right ventricle were lower than expected, especially PFR, we additionally compared the correlation between RVPER(P), RVPFR(P), RVPER(T), RVPFR(T) and other functional parameters of the right ventricle, as shown in Table 4.

\section{Repeatability comparison}

\section{Repeatability of LVEF, RVEF, and left and right ventricular volume parameters}

The data of observer 1 and observer 2 were shown in Table 5, and the intraclass correlation coefficients of LVEF, RVEF, and left and right ventricular volume parameters were excellent $(0.823 \sim 0.989, \mathrm{P}<0.001)$.

Bland-Altman consistency analyses was used to evaluate inter-observer repeatability bias. The $95 \%$ confidence intervals of $\operatorname{LVEF}(\mathrm{P})$ and $\operatorname{RVEF}(\mathrm{P})$ were [-8.332 8.132] and [-10.652 13.652], and the out-ofrange ratios were $10.4 \%(8 / 77)$ and $5.2 \%(4 / 77)$. The $95 \%$ confidence intervals of $\operatorname{LVEF}(\mathrm{T})$ and RVEF(T) were [-4.8 5.0] and [-7.032 9.432], and the out-of-range ratios were 5.2\% (4/77) and 9.1\% (7/77), respectively. The 95\% confidence intervals of LVEDV, LVESV and LVSV were [-31.032 34.432], [-24.088 26.088] and [-15.172 16.972], and the out-of-range ratios were 6.5\% (5/77), 5.2\% (5/77) and 5.2\%(4/77), respectively. The $95 \%$ confidence intervals of RVEDV, RVESV and RVSV were (-37.452 35.852), (-33.556 
29.556) and (-12.816 15.016), and the out-of-range ratios were $7.8 \%(6 / 77), 6.5 \%(6 / 77)$ and $6.5 \%$ (6/77), respectively. The Bland-Altman analysis diagram of each parameter repeatability was shown in Fig. 4.

\section{Repeatability of determination of LVPER, LVPFR, RVPER, and RVPFR}

The data of observer 1 and observer 2 were shown in Table 6. 11 groups of LVPFR (T) and 8 groups of RVPFR (T) data could not be calculated from observer 1 and/or observer 2 due to failed recognition of the software, which was not included in the analysis. The intra-group correlation coefficients of PER, PFR, $\mathrm{PER}$, and PFR of the left ventricle were excellent $(0.912 \sim 0.964, \mathrm{P}<0.001)$. The intraclass correlation coefficients of PER(P), PER(T), and PFR(T) of the right ventricle were all excellent $(0.838 \sim 0.860, P<$ $0.001)$, while the intraclass correlation coefficient of PFR $(P)$ was good $(0.698, P<0.001)$.

Bland-Altman consistency analysis was used to evaluate interobserver repeatability bias. The $95 \%$ confidence intervals of LVPER(P), LVPFR(P), LVPER(T) and LVPFR(T) were [-0.4504 0.4904], [-0.5036 $0.5156],[-0.4146 \sim 0.4086]$ and [-0.4382 0.4242], and the out-of-range ratios were $9.1 \%(7 / 77), 6.5 \%$ (5/77), 6.5\% (5/77) and 9.1\% (6/66), respectively. The 95\% confidence intervals of RVPER(P), RVPFR(P), $\operatorname{RVPER}(\mathrm{T})$ and RVPFR(T) were [-0.7044 0.8244], [-0.594 0.974], [-0.7736 0.8366] and [-0.7044 $0.8244]$, and the out-of-range ratios were $6.5 \%(5 / 77), 6.5 \%$ (5/77), 7.8\% (6/77) and 4.3\% (3/69), respectively. The bland-Altman analysis diagram of each parameter repeatability was shown in Fig. 5 .

\section{Discussion}

$\mathrm{EF}$ is one of the most important parameters to characterize cardiac function, and its "gold" standard measurement method is invasive ventriculography. In contrast, the commonly accepted "gold" standard of the non-invasive method is cardiac magnetic resonance(CMR). The former is invasive and costly, while the latter is limited in clinical use because of its complicated techniques and many contradictions. As a non-invasive examination, 99mTc-RBC MUGA using radionuclide to label autologous red blood cells is equivalent to simulating the change of blood volume in the ventricle, which is the closest quantitative method to the concept of EF. Tomography can reconstruct left and right ventricles in 3D mode, which is undoubtedly much closer to the complete standard measurement mode.

In this study, the LVEF obtained by the two methods of the two cameras had excellent correlation and no significant statistical difference, which was coincide with the previous studies[15-17]. The correlation of RVEF was good but worse than that of LVEF ( $r$ value: 0.619 vs 0.831 ), and there was a statistically significant difference between them. This result was consistent with previous studies[17], but in which Chen et al. thought that the reason for this situation was that the algorithm of QBS software was inaccurate due to the influence of LV size and shape when identifying RV boundary in CZT-SPECT, which leaded to the reduction of correlation with the planar method. Although It could be part of the reason, the influence of RV in the planar method seemed to be more obvious, such as it was more difficult to accurately identify the position of the RV pulmonary trunk, which tend to cause more errors in the 
delineation of the RV basal part than that in the CZT-SPECT tomographic method. Therefore, concerning the correlation and difference of RVEF, we thought that the reason based on the C-SPECT planar method may be more significant, which can be indirectly proved by the results of repeatability of their respective methods in the later part. In addition, previous studies comparing CZT-SPECT tomographic imaging with CMR, RVEF, and right ventricular volume had a reasonable correlation[16, 18-19].

There are few studies on PER and PFR in tomographic MUGA with CZT-SPECT, which may be related with that there is no public-recognized "gold" standard for these two parameters and CZT-SPECT myocardial perfusion imaging (MPI) can also provide many functional parameters of left ventricles, such as PER and PFR, and MPI is more convenient and popular than MUGA, so there are many studies on this aspect in recent years[20-21], especially the study of left ventricular systolic and diastolic function under stress[22], but there are few studies on right ventricular PER and PFR in various examination techniques until now. In our study, the LVPER and LVPFR obtained by the two cameras and methods had a reasonable correlation $(r=0.672$ and 0.700$)$, but the correlation was worse than LVEF, which was still within our expectations. Compared with LVEF obtained from 2 frames of EDV and ESV targeted images, the cumulative deviation of LVPER and LVPFR obtained from 16 frames of reconstructed count (volume)time curve will be more significant. However, the correlation between RVPER and RVPFR was only 0.463 and 0.253 between the two methods, and the RVPFR between the two methods had a noticeable statistical difference, which was lower than our expectation. Therefore, we compared RVPER(P), RVPFR(P), RVPER(T) and RVPFR(T) with RVEF, RVEDV, and RVESV, respectively, and got the trend that these four parameters were positively correlated with RVEF and negatively correlated with RVEDV and RVESV, which was in line with the essential physiological function of the heart and excluded the possibility of human error in data processing by the observers. Even so, we could see that the correlation of RVPER(P) and RVPER(T) in each group was good or general, and the correlation of RVPFR $(P)$ and RVPFR $(T)$ in each group was only general or poor, even RVPFR(P) had no apparent correlation with RVEDV and RVESV. To sum up, the deviation of measuring RVPER and RVPFR both in C-SPECT and CZTSPECT showed evident uncertainty and no clear rule. Sometimes the former measured too much, and sometimes the latter measured too much, which was particularly obvious in RVPFR, and the deviation value was significant. The above may indicate that we need a third-party comparison. However, before that, we are unsure whether it was related to our sample selection because of this low correlation, so we thought it may be necessary to have a group of samples with completely normal right heart or nonecardiovascular diseases to be the normal group for control.

In terms of repeatability, the intraclass correlation coefficient of RVPFR $(P)$ was good $(I C C=0.698)$, while the intraclass correlation coefficient of other groups of data was excellent $(0.823 \sim 0.989)$ which was similar to previous studies[13, 15, 17, 23]. It could be drawn from the Bland-Altman diagram that the repeatability confidence intervals of LVEF and RVEF of CZT-SPECT were narrower than those of C-SPECT, indicating that CZT-SPECT had better repeatability. The repeatability confidence interval of LVEF of the two cameras was narrower than the corresponding confidence interval of RVEF, which showed that the repeatability of LVEF was better than RVEF. The repeatability confidence intervals of LVPER and LVPFR of the two cameras and methods were not much different in width, the LVPER group was slightly better than 
the corresponding LVPFR group, and the RVPER and RVPFR were similar. However, the repeatability confidence intervals of the four parameters in the LV group were all narrower than those in the RV group, which showed that the repeatability of LVPER and LVPFR in both cameras was better than that of RVPER and RVPFR. As the repeatability of PER and PFR in left and right ventricles in their respective cameras and methods was good, combined with the problem of imperfect correlation between the above two cameras and methods, it further showed that we need to compare third-party data or establish CZTSPECT reference standards for PER and PFR. The left and right ventricular volume parameters of CZTSPECT were not compared with the reference group but evaluated the number of cases outside their confidence intervals, which was considered to be still within the clinical acceptance range $(5.2 \% \sim 7.8 \%)$.

In this study, coefficient of variation (CV), an index used in previous studies by Jensen et al. [15, 23], was introduced, but the definition of $\mathrm{CV}$ in their studies seemed to be different from the conventional definition, and CV was regarded as an index reflecting the discreteness of a group of data. When the standard deviation (SD) is not suitable for direct comparison between two groups of data, CV can be used for comparison instead. It is defined as the ratio of standard deviation to the average value (SD/AV) of this group of data. However, in Jensen et al.' s research, CV value was obtained by dividing the standard deviation of the difference between paired data groups by the average value of the paired data groups, that was, standard deviation (A2-A1)/ average value $((\mathrm{A} 2+\mathrm{A} 1) / 2)$. They used the CV value obtained to evaluate the repeatability of each paired data set. For example, they obtained LVEF, RVEF, left and right ventricular volumes measured by observers 1 and 2, to calculate the CV values by the above method, then they used the $\mathrm{CV}$ to evaluate the repeatability of the single parameter and also compared with other parameters.

In our study, the corresponding CV values of each group were obtained by this method, and the trends of EF and volume parameters of left and right ventricles were roughly the same as those in Jensen et al.' $s$ study, but the values were higher, which was caused by the difference in case sample selection. They chose tumor patients without cardiovascular diseases, and their heart function was normal. All of our samples were patients with cardiovascular diseases, and there were many patients with a severe decrease in heart function caused by ischemic cardiomyopathy, dilated cardiomyopathy, or heart failure due to other reasons. In our results, the CV values of $\operatorname{LVEF}(P), \operatorname{LVEF}(T), \operatorname{RVEF}(P)$, and $\operatorname{RVEF}(T)$ were $11.1 \%$, $6.7 \%, 14.9 \%$, and $9.5 \%$, respectively, which were significantly lower in CZT-SPECT group than in C-SPECT group, while LVEF group was lower than corresponding RVEF group respectively. The above was also indicated in the Bland-Altman diagram, and here we could see that the CV value of RVEF in the CZTSPECT group was even lower than that of LVEF in the C-SPECT group, indicating that CZT-SPECT was better than C-SPECT in terms of repeatability among observers. The CV values of LVEDV(T), LVESV(T), $\operatorname{LVSV}(\mathrm{T}), \operatorname{RVEDV}(\mathrm{T}), \mathrm{RVESV}(\mathrm{T})$ and RVSV(T) were $6.1 \%, 10.2 \%, 14.1 \%, 16.0 \%, 23.4 \%$ and $14.7 \%$, respectively. The results showed that the repeatability of left ventricular measurement was better than that of the right ventricle. The first reason is that the right ventricular boundary recognition, especially the right atrial ventricular boundary and pulmonary trunk location, mentioned above, and it has always been a problem in cardiac blood pool imaging, from planar imaging to tomographic imaging. Another reason is that the repeatability for small chambers is worse for larger chambers, which was also mentioned in 
Jensen et al.' s research. Most of the samples in this study had normal right heart function, and some right heart chambers were relative smaller, which also had a certain influence on the measurement repeatability. In addition, most of these samples had serious left ventricular involvement and enlarged heart chambers; the ratio of left and right cardiac chambers was increased. The right ventricular recognition was more obviously affected by the enlarged left ventricle, which further affected the repeatability of right ventricular measurement. However, the effects for RVEDV and RVESV were closely similar, so the CV values of RVSV and LVSV were very close, which explained why the repeatability of $\operatorname{RVEF}(T)$ was not significant compared with $\operatorname{LVEF}(\mathrm{T})(\mathrm{CV}$ value: $9.5 \%$ vs $6.7 \%)$.

For PER and PFR, the CV values of LVPER(P), LVPFR(P), LVPER(T), and LVPFR(T) were $12.6 \%, 17.2 \%$, $11.6 \%$, and $15.7 \%$, respectively, and the values of RVPER $(P), \operatorname{RVPFR}(P), \operatorname{RVPER}(T)$ and RVPFR(T) were $18.6 \%, 25.3 \%, 18.6 \%$ and $21.7 \%$. PER group was better than PFR group, and LV group was better than RV group. There are 8 cases for observer 1 and 7 cases for observer 2 of LVPFR(T) in the processed data, respectively, which could not be obtained( 4 same cases could not be obtained both). RVPFR(T) could not be obtained in 5 cases for observer 1 and 6 cases for observer 2(3 same cases in both). The software identifies it as NA, which meant unrecognized or invalid data. The reasons for this situation were not mentioned in previous studies and software instructions, and we cannot exactly explain these reasons either. By observing and analysing the volume(and filling) -time curve(Fig. 1) of each sample, we tried to find the potential trend to explain the NA data emerged. We preferred one possibility based on distinguishing the early peak filling rate(PFR) and late peak filling rate(PFR1) by BPGs software. In the volume(and filling) -time curve, BPGs recognized the maximum negative value of the filling curve, which obtained from the volume curve, as PER(the deepest trough in the filling curve), then the following two positive peaks (peak 1 and peak 2) would be further identified as the value points of PFR and PFR1 (or only identified PFR if only single peak). We found that most of these NA data have the following characteristic: there was a trough with negative value between peak 1 and peak 2 , and the absolute value of this trough was not much different from peak 1 or significantly larger than peak 1 . In the few of these NA data, there might be another characteristic: peak 1 and peak 2 were not significantly different in absolute value, and there was a less obvious trough with positive value between them. The cause of this waveform of the filling curve should be related to the sample we selected, based on the waveform of the volume curve disorder caused by significant impairment of ventricular diastolic function in patients with severe cardiovascular disease. Compare with CZT-SPECT, there was no NA data of PFR in C-SPECT, which reason might be, the processing of planar PFR was relatively simple, and only the highest peak in the filling curve in the whole diastolic process would be selected. According to the different calculation methods and principles, we chose the larger one between PFR and PFR1 of CZT-SPECT mentioned above as the PFR data for the comparative analysis, to match the calculation mode of C-SPECT planar method. In any case, this finding in our study suggested that PFR parameters obtained by CZT-SPECT might be not a stable parameter for monitoring ventricular diastolic function, but PER was much more stable, and it was also reported from our analysis that its repeatability was better than PFR. However, previous studies had shown that the diastolic dysfunction of the ventricle was earlier marker than the systolic 
dysfunction for heart diseases[24]. Therefore, we need further study in processing data with BPGs or other relative software in order to obtain stable PFR parameters.

\section{Study limitations}

This study had some limitations. Firstly, due to the limitation of clinical situations, there was no CMR and/or left ventricular angiography results as a "gold" standard for comparison; Secondly, the diastolic function was still lacking "gold" standard reference techniques. In addition, due to ethical restrictions, there was no normal group with non-cardiac diseases. However, as far as we know, in CZT-SPECT tomographic MUGA studies published so far, this study included the most significant number of samples of patients with cardiovascular diseases.

\section{Conclusion}

In summary, CZT-SPECT tomographic MUGA has a good correlation with C-SPECT cardiac planar MUGA in evaluating left and right ventricular systolic function and left ventricular diastolic function. Its repeatability is better than that of C-SPECT. The determination of right ventricular diastolic function still needs further study. Because of the excellent temporal, spatial, and energy resolution of CZT-SPECT and the high detection efficiency of photon counting, tomographic MUGA with CZT-SPECT will play an important and unique role in the clinical application of accurate evaluation of bi-ventricular function in the future.

\section{Declarations}

Funding This research are supported by Research Project of TEDA International Cardiovascular Hospital (2021-TD-004).

Conflicts of Interest The authors declare that they have no conflict of interest.

Ethics approval This study was approved by the local ethics committee of our institution, and conformed to the ethical principles outlined in the Declaration of Helsinki.

Consent to participate Written informed consent was obtained from individual or guardian participants.

Consent for publication Not applicable.

Availability of data and material All data are fully available without restriction.

Code availability 4DR Xeleris Workstation (GE Healthcare, Milwaukee, WI, USA); Cedars-Sinai G-BPGs software(Version2019, Cedars-Sinai, Ca, USA ).

\section{Authors' contributions}

Yue Chen performed the experiment and performed the data analyses and wrote the manuscript; 
Zekun Pang performed the experiment and performed the data analyses and wrote the manuscript; Jiao Wang helped perform the analysis with constructive discussions;

Jianming Li contributed to the conception of the study and performed the experiment;

All authors read and approved the manuscript.

\section{References}

1. DE GEUS-OEI LF, MAVINKURVE-GROOTHUIS AM, BELLERSEN L, et al. Scintigraphic techniques for early detection of cancer treatment-induced cardiotoxicity[J]. J Nucl Med Technol, 2013,41(3):170-81.

2. ALVAREZ JA, RUSSELL RR. Cardio-oncology: The nuclear option[J]. Curr Cardiol Rep, 2017,19(4):31.

3. NAYA M, MANABE O, KOYANAGAWA K, et al. The role of nuclear medicine in assessments of cardiac dyssynchrony[J]. J Nucl Cardiol, 2018,25(6):1980-1987.

4. STEELANT B, STANKOVIC I, ROIJAKKERS I, et al. The Impact of Infarct Location and Extent on LV Motion Patterns: Implications for Dyssynchrony Assessment[J]. JACC Cardiovasc Imaging, 2016,9(6):655-64.

5. TONGE CM, FERNANDEZ RC, HARBINSON MT. Commentary: current issues in nuclear cardiology[J]. Br J Radiol, 2008,81(964):270-4.

6. DAOU D, VAN KRIEKINGE SD, COAGUILA C, et al. Automatic quantifification of right ventricular function with gated blood pool SPECT[J]. J Nucl Cardiol, 2004,11(3):293-304.

7. SIBILLE L, BOUALLEGUE FB, BOURDON A, et al. Comparative values of gated blood-pool SPECT and CMR for ejection fraction and volume estimation[J]. Nucl Med Commun, 2011,32(2):121-8.

8. DUVALL WL, GUMA-DEMERS KA, GEORGE T, et al. Radiation reduction and faster acquisition times with SPECT gated blood pool scans using a high-effificiency cardiac SPECT camera[J]. J Nucl Cardiol, 2016,23(5):1128-1138.

9. LAIREZ O, DELMAS C, FOURNIER P, et al. Feasibility and accuracy of gated blood pool SPECT equilibrium radionuclide ventriculography for the assessment of left and right ventricular volumes and function in patients with left ventricular assist devices[J]. J Nucl Cardiol, 2018,25(2):625-634.

10. EINSTEIN AJ, BLANKSTEIN R, ANDREWS $H$, et al. Comparison of image quality, myocardial perfusion, and left ventricular function between standard imaging and single-injection ultra-low-dose imaging using a high-effificiency SPECT camera: The MILLISIEVERT study[J]. J Nucl Med, 2014,55(9):1430-7.

11. BAILLY M, LE ROUZIC G, METRARD G. Gated Tomographic Radionuclide Angiography Using CZT Gamma Camera in Patients Receiving Cardiotoxic Chemotherapy: Going Faster and Less Irradiating[J]. Clin Nucl Med, 2019,44(6):472-474.

12. TISSOT H, ROCH V, MOREL $O$, et al. Left ventricular ejection fraction determined with the simulation of a very low-dose CZT-SPECT protocol and an additional count-calibration on planar radionuclide angiographic data[J]. J Nucl Cardiol, 2019,26(5):1539-1549. 
13. HANSEN NL, HAARMARK C, ZERAHN B. Ventricular peak emptying and filling rates measured by gated tomographic radionuclide angiography using a cadmium-zinc-telluride SPECT camera in chemotherapy-naïve cancer patients[J]. J Nucl Cardiol, 2020 Aug;27(4):1193-1201.

14. Rydberg J, Andersen J, Haarmark C, et al. The influence of anthropometric and basic circulatory variables on count rate in cadmium-zinc-telluride SPECT gated radionuclide angiography[J]. J Nucl Cardiol, 2019 Dec;26(6):1974-1980.

15. JENSEN MM, SCHMIDT U, HUANG C, et al. Gated tomographic radionuclide angiography using cadmium-zinc-telluride detector gamma camera; comparison to traditional gamma cameras[J]. J Nucl Cardiol, 2014,21(2):384-96.

16. HAARMARK C, HAASE C, JENSEN MM, et al. Pre-chemotherapy values for left and right ventricular volumes and ejection fraction by gated tomographic radionuclide angiography using a cadmiumzinc-telluride detector gamma camera[J]. J Nucl Cardiol, 2016,23(1):87-97.

17. CHEN YC, KO CL, YEN RF, et al. Comparison of biventricular ejection fractions using cadmium-zinctelluride SPECT and planar equilibrium radionuclide angiography[J]. J Nucl Cardiol, 2016,23(3):34861.

18. ANDERSON K, PRYLUTSKA H, DUCHARME A, et al. Evaluation of the right ventricle: comparison of gated blood-pool single photonelectron computed tomography and echocardiography with cardiac magneticresonance[J]. Int J Cardiol. 2014,171(1):1-8.

19. Apert A, Canu M, Jankowski A, et al. Comparison of Cadmium Zinc Telluride ECG-gated SPECT equilibrium radionuclide angiocardiography to magnetic resonance imaging to measure right ventricular volumes and ejection fraction in patients with cardiomyo-pathy[J]. J Nucl Cardiol, 2021 May 14, Online ahead of print.

20. Nitta K, Kurisu S, Nakamoto Y, et al. Coronary Artery Calcium Is Associated with Left Ventricular Diastolic Function Independent of Myocardial Ischemia[J]. Int Heart J, 2019, May 30, 60(3): 554559.

21. Malek H, Samiei N, Yaghoobi N, et al. Assessment of LV diastolic dysfunction in myoc-ardial perfusion imaging: a correlative study with transthoracic echocardiography[J]. N-ucl Med Commun, 2021 May 13, Online ahead of print.

22. Bestetti A, Cuko B, Gasparini M, et al. Direct correlation between ischemic burden induc-ed by dipyridamole and stress peak filling rate: a gated perfusion single-photon emis-sion computed tomography study[J]. Nucl Med Commun, 2021 Feb 01, 42(2): 173-181.

23. JENSEN MM, HAASE C, ZERAHN B. Interstudy repeatability of left and right ventricular volume estimations by serial-gated tomographic radionuclide angiographies using a cadmium-zinc-telluride detector gamma camera[J]. Clin Physiol Funct Imaging, 2015,35(6):418-24.

24. Uebleis C, Hellweger S, Laubender RP, et al. Left ventricular dyssynchrony assessed by gated SPECT phase analysis is an independent predictor of death in patients with advanced coronary artery disease and reduced left ventricular function not undergoing cardiac resynchronization therapy[J]. Eur J Nucl Med Mol Imaging, 2012, 39(10): 1561-1569.

Page $12 / 23$ 


\section{Tables}

Table 1. Basic characteristics of the patients

\begin{tabular}{|c|c|}
\hline Patient data & $\triangle \mathrm{n}=77 \rrbracket$ \\
\hline Age (y) & $61.3 \pm 11.4$ \\
\hline male & $49 \rrbracket 63.6 \% \rrbracket$ \\
\hline female & $28 \rrbracket 36.4 \% \rrbracket$ \\
\hline Height (cm) & $167.7 \pm 8.6$ \\
\hline Weight (kg) & $73.3 \pm 15.1$ \\
\hline Injection dose (mCi) & $22.8 \pm 2.3$ \\
\hline \multicolumn{2}{|l|}{ Risk factor } \\
\hline hypertension & $40 \otimes 51.9 \% \bigotimes$ \\
\hline hyperlipemia & $9 \rrbracket 11.7 \% \rrbracket$ \\
\hline diabetes & $19 \rrbracket 24.7 \% \rrbracket$ \\
\hline smoking & $24 \rrbracket 31.2 \% \bigotimes$ \\
\hline drinking & $12 \rrbracket 15.6 \% \bigotimes$ \\
\hline \multicolumn{2}{|l|}{ medical/case history } \\
\hline myocardial infarction(MI) & $13 \otimes 16.9 \% \bigotimes$ \\
\hline pacemaker implantation & $6 \rrbracket 7.8 \% \rrbracket$ \\
\hline stent therapy & $14 \rrbracket 18.2 \% \rrbracket$ \\
\hline coronary artery by-pass grafting & $3 \rrbracket 3.9 \% \rrbracket$ \\
\hline \multicolumn{2}{|l|}{ clinical diagnosis } \\
\hline coronary heart disease(CAD) & $33 \rrbracket 42.9 \% \rrbracket$ \\
\hline dilated cardiomyopathy(DCM) & $26 \rrbracket 33.8 \% \rrbracket$ \\
\hline arrhythmia & $26 \rrbracket 33.8 \% \rrbracket$ \\
\hline others (valvular disease, rheumatic heart disease, etc.) & $3 \llbracket 3.9 \% \square$ \\
\hline
\end{tabular}

Table 2. Comparison of LVEF and RVEF between CZT-SPECT and C-SPECT 


\begin{tabular}{|lll|}
\hline Statistical parameters and values & LVEF & RVEF \\
\hline Z value (or T value) & -1.162 & -2.772 \\
\hline P value & 0.245 & 0.007 \\
\hline r value(correlation) & $0.831 \llbracket \mathrm{P} \llbracket 0.001 \rrbracket$ & $0.619 \llbracket \mathrm{P} \llbracket 0.001 \rrbracket$ \\
\hline Difference mean & -0.6 & 3.1 \\
\hline Standard deviation & 8.2 & 9.7 \\
\hline Upper limit of 95\% confidence interval & 15.472 & 22.112 \\
\hline Lower limit of 95\% confidence interval & -16.672 & -15.912 \\
\hline
\end{tabular}

Table 3. Comparison of LVPER, LVPFR, RVPER and RVPFR between CZT-SPECT and C-SPECT

\begin{tabular}{|c|c|c|c|c|}
\hline Statistical parameters and values & LVPER & LVPFR & RVPER & RVPFR \\
\hline$Z$ value (or T value) & 1.353 & -1.641 & -1.374 & -3.321 \\
\hline$P$ value & 0.18 & 0.101 & 0.173 & 0.001 \\
\hline r value(correlation) & $\begin{array}{l}0.672 \rrbracket P \rrbracket \\
0.001 \rrbracket\end{array}$ & $\begin{array}{l}0.700 \otimes P \rrbracket \\
0.001 \rrbracket\end{array}$ & $\begin{array}{l}0.463 \rrbracket P \rrbracket \\
0.001 \rrbracket\end{array}$ & $\begin{array}{l}0.253 \rrbracket \mathrm{P} \rrbracket \\
0.05 \rrbracket\end{array}$ \\
\hline Difference mean & -0.09 & -0.1 & 0.12 & 0.24 \\
\hline Standard deviation & 0.58 & 0.46 & 0.77 & 0.64 \\
\hline $\begin{array}{l}\text { Upper limit of } 95 \% \text { confidence } \\
\text { interval }\end{array}$ & 1.0468 & 0.8016 & 1.6292 & 1.4944 \\
\hline $\begin{array}{l}\text { Lower limit of } 95 \% \text { confidence } \\
\text { interval }\end{array}$ & -1.2268 & -1.0016 & -1.3892 & -1.0144 \\
\hline
\end{tabular}

Table 4. Correlation of RVPER (P), RVPFR(P), RVPER(T) and RVPFR(T) with RVEF and right ventricular volume parameters

A RVPER(P) compared with RVEF(P), RVEDV and RVESV respectively

\begin{tabular}{|c|c|c|c|}
\hline \multirow[t]{2}{*}{ Parameter } & \multicolumn{3}{|l|}{ RVPER囚P囚 } \\
\hline & RVEF『P』 & RVEDV & RVESV \\
\hline Correlation r value & $0.714 \otimes P \rrbracket 0.001 \rrbracket$ & $-0.478 \otimes P \otimes 0.001 \rrbracket$ & $-0.578 \rrbracket P \otimes 0.001 \rrbracket$ \\
\hline
\end{tabular}

B RVPER(T) compared with RVEF(T), RVEV and RVESV respectively 


\begin{tabular}{|c|c|c|c|}
\hline \multirow[t]{2}{*}{ Parameter } & \multicolumn{3}{|l|}{ RVPER囚T囚 } \\
\hline & RVEF®T $\triangle$ & RVEDV & RVESV \\
\hline Correlation r value & $0.708 \otimes P \otimes 0.001 \rrbracket$ & $-0.457 \otimes P \otimes 0.001 \rrbracket$ & $-0.609 \rrbracket P \otimes 0.001 \rrbracket$ \\
\hline
\end{tabular}

C RVPFR(P) compared with RVEF(P), RVEDV and RVESV respectively

\begin{tabular}{|c|c|c|c|}
\hline \multirow[t]{2}{*}{ Parameter } & \multicolumn{3}{|l|}{ RVPFR『P』 } \\
\hline & RVEF『P】 & RVEDV & RVESV \\
\hline Correlation r value & $0.479 \bigotimes \mathrm{P} \bigotimes 0.001 \rrbracket$ & $-0.056 \rrbracket P \llbracket 0.05 \rrbracket$ & $-0.140 \bigotimes \mathrm{P} \bigotimes 0.05 \rrbracket$ \\
\hline
\end{tabular}

D RVPFR(T) compared with RVEF(T), RVEDV and RVESV respectively

\begin{tabular}{|c|c|c|c|}
\hline \multirow[t]{2}{*}{ Parameter } & \multicolumn{3}{|l|}{ RVPFR $\triangle T \rrbracket$} \\
\hline & RVEF囚T』 & RVEDV & RVESV \\
\hline Correlation r value & $0.495 \rrbracket P \rrbracket 0.001 \rrbracket$ & $-0.263 \rrbracket P \rrbracket 0.05 \rrbracket$ & $-0.366 \rrbracket P=0.002 \rrbracket$ \\
\hline
\end{tabular}

Table 5. Repeatability analysis between two observers

A. Left ventricular EF and volume parameters 


\begin{tabular}{|c|c|c|c|c|c|}
\hline $\begin{array}{l}\text { Groups, statistical } \\
\text { parameters and values }\end{array}$ & 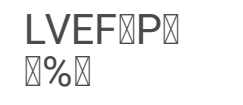 & 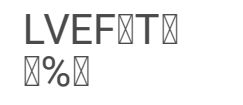 & LVEDVヌml & LVESV『ml『 & 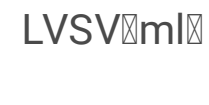 \\
\hline Observer 1 & $37.8 \pm 13.0$ & $\begin{array}{l}35.0 \rrbracket 24 \rrbracket \\
48 \rrbracket\end{array}$ & $\begin{array}{l}158.0 \\
\otimes 116.5 \rrbracket \\
220.0 \rrbracket\end{array}$ & $\begin{array}{l}100.0 \\
\otimes 61.0 \rrbracket \\
157.5 \rrbracket\end{array}$ & $57.5 \pm 20.3$ \\
\hline Observer 2 & $\begin{array}{l}36.0 \rrbracket 25.0 \rrbracket \\
47.5 \rrbracket\end{array}$ & $\begin{array}{l}33.0 \rrbracket 23.5 \rrbracket \\
47.5 \rrbracket\end{array}$ & $\begin{array}{l}163.0 \\
\bigotimes 117.5 \rrbracket \\
226.0 \rrbracket\end{array}$ & $\begin{array}{l}102.0 \\
\rrbracket 64.5 \rrbracket \\
158.5 \rrbracket\end{array}$ & $58.4 \pm 21.1$ \\
\hline $\begin{array}{l}\text { Correlation coefficient } \\
(95 \% \mathrm{Cl})\end{array}$ & $\begin{array}{l}0.956 \\
\rrbracket 0.931 \rrbracket \\
0.972 \rrbracket\end{array}$ & $\begin{array}{l}0.989 \\
\rrbracket 0.983 \rrbracket \\
0.993 \rrbracket\end{array}$ & $\begin{array}{l}0.984 \\
\varangle 0.974 \rrbracket \\
0.990 \rrbracket\end{array}$ & $\begin{array}{l}0.989 \\
\rrbracket 0.983 \rrbracket \\
0.993 \rrbracket\end{array}$ & $\begin{array}{l}0.921 \\
\rrbracket 0.878 \rrbracket \\
0.949 \rrbracket\end{array}$ \\
\hline$P$ value & $\otimes 0.001$ & $\varangle 0.001$ & $\otimes 0.001$ & $\varangle 0.001$ & $₫ 0.001$ \\
\hline Difference mean & -0.1 & 0.1 & 1.7 & 1 & 0.9 \\
\hline Standard deviation & 4.2 & 2.5 & 16.7 & 12.8 & 8.2 \\
\hline $\begin{array}{l}\text { Upper limit of } 95 \% \\
\text { confidence interval }\end{array}$ & 8.132 & 5 & 34.432 & 26.088 & 16.972 \\
\hline $\begin{array}{l}\text { Lower limit of } 95 \% \\
\text { confidence interval }\end{array}$ & -8.332 & -4.8 & -31.032 & -24.088 & -15.172 \\
\hline $\begin{array}{l}\text { Coefficient of variation } \\
(\%)\end{array}$ & 11.1 & 6.7 & 6.1 & 10.2 & 14.1 \\
\hline
\end{tabular}

B. Right ventricular EF and volume parameters 


\begin{tabular}{|c|c|c|c|c|c|}
\hline $\begin{array}{l}\text { Groups, statistical } \\
\text { parameters and values }\end{array}$ & $\begin{array}{l}\text { RVEF『PУ } \\
\text { \\
% }\end{array}$ & $\begin{array}{l}\text { RVEF } \triangle T \text { T) } \\
\bigotimes \% \bigotimes\end{array}$ & RVEDV『ml『 & 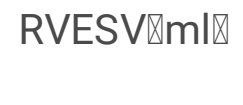 & RVSV『ml『 \\
\hline Observer 1 & $40.6 \pm 20.8$ & $43.7 \pm 11.4$ & $\begin{array}{l}103.0 \\
\otimes 83.0 \rrbracket \\
140.0 \rrbracket\end{array}$ & $\begin{array}{l}59.0 \rrbracket 43.5 \rrbracket \\
82.0 \rrbracket\end{array}$ & $\begin{array}{l}46.0 \rrbracket 36.0 \rrbracket \\
56.5 \rrbracket\end{array}$ \\
\hline Observer 2 & $42.12 \pm 10.3$ & $44.8 \pm 11.4$ & $\begin{array}{l}106.0 \\
\otimes 82.5 \rrbracket \\
137.5 \rrbracket\end{array}$ & $\begin{array}{l}58.0 \rrbracket 43.0 \rrbracket \\
79.0 \rrbracket\end{array}$ & $\begin{array}{l}49.0 \otimes 38.0 \rrbracket \\
57.5 \rrbracket\end{array}$ \\
\hline $\begin{array}{l}\text { Correlation coefficient } \\
(95 \% \mathrm{Cl})\end{array}$ & $\begin{array}{l}0.823 \\
\rrbracket 0.732 \rrbracket \\
0.884 \rrbracket\end{array}$ & $\begin{array}{l}0.929 \\
\rrbracket 0.887 \rrbracket \\
0.955 \rrbracket\end{array}$ & $\begin{array}{l}0.933 \\
\varangle 0.897 \rrbracket \\
0.957 \rrbracket\end{array}$ & $\begin{array}{l}0.926 \\
\rrbracket 0.886 \rrbracket \\
0.952 \rrbracket\end{array}$ & $\begin{array}{l}0.899 \\
\rrbracket 0.846 \rrbracket \\
0.934 \rrbracket\end{array}$ \\
\hline$P$ value & $\nabla 0.001$ & $\varangle 0.001$ & $\otimes 0.001$ & $\varangle 0.001$ & $₫ 0.001$ \\
\hline Difference mean & 1.5 & 1.2 & -0.8 & -2 & 1.1 \\
\hline Standard deviation & 6.2 & 4.2 & 18.7 & 16.1 & 7.1 \\
\hline $\begin{array}{l}\text { Upper limit of } 95 \% \\
\text { confidence interval }\end{array}$ & 13.652 & 9.432 & 35.852 & 29.556 & 15.016 \\
\hline $\begin{array}{l}\text { Lower limit of } 95 \% \\
\text { confidence interval }\end{array}$ & -10.652 & -7.032 & -37.452 & -33.556 & -12.816 \\
\hline $\begin{array}{l}\text { Coefficient of variation } \\
(\%)\end{array}$ & 14.9 & 9.5 & 16.0 & 23.4 & 14.7 \\
\hline
\end{tabular}

\section{Table 6. Repeatability analysis among observers}

A. left ventricular PER and PFR 


\begin{tabular}{|c|c|c|c|c|}
\hline $\begin{array}{l}\text { Groups, statistical parameters } \\
\text { and values }\end{array}$ & LVPER囚P囚 & LVPFR囚P囚 & LVPER $\triangle \mathbb{T} \otimes$ & LVPFR $\triangle T$ T \\
\hline Observer 1 & $1.90 \pm 0.66$ & $\begin{array}{l}1.45 \rrbracket 1.05 \rrbracket \\
1.89 \rrbracket\end{array}$ & $1.81 \pm 0.76$ & $1.43 \pm 0.62$ \\
\hline Observer 2 & $1.92 \pm 0.74$ & $\begin{array}{l}1.40 \rrbracket 1.02 \rrbracket \\
1.87 \rrbracket\end{array}$ & $\begin{array}{l}1.69 \rrbracket 1.11 \rrbracket \\
2.45 \rrbracket\end{array}$ & $\begin{array}{l}1.32 \otimes 1.01 \rrbracket \\
1.86 \rrbracket\end{array}$ \\
\hline Correlation coefficient $(95 \% \mathrm{Cl})$ & $\begin{array}{l}0.940 \rrbracket 0.907 \rrbracket \\
0.961 \rrbracket\end{array}$ & $\begin{array}{l}0.912 \rrbracket 0.865 \rrbracket \\
0.943 \rrbracket\end{array}$ & $\begin{array}{l}0.964 \rrbracket 0.944 \rrbracket \\
0.977 \rrbracket\end{array}$ & $\begin{array}{l}0.943 \rrbracket 0.909 \rrbracket \\
0.965 \rrbracket\end{array}$ \\
\hline$P$ value & $\bigotimes 0.001$ & $₫ 0.001$ & $\varangle 0.001$ & $\bigotimes 0.001$ \\
\hline Difference mean & 0.02 & 0.006 & -0.003 & -0.007 \\
\hline Standard deviation & 0.24 & 0.26 & 0.21 & 0.22 \\
\hline $\begin{array}{l}\text { Upper limit of } 95 \% \text { confidence } \\
\text { interval }\end{array}$ & 0.4904 & 0.5156 & 0.4086 & 0.4242 \\
\hline $\begin{array}{l}\text { Lower limit of } 95 \% \text { confidence } \\
\text { interval }\end{array}$ & -0.4504 & -0.5036 & -0.4146 & -0.4382 \\
\hline Coefficient of variation (\%) & 12.6 & 17.2 & 11.6 & 15.7 \\
\hline
\end{tabular}

B. Right ventricular PER and PFR

\begin{tabular}{|c|c|c|c|c|}
\hline $\begin{array}{l}\text { Groups, statistical parameters } \\
\text { and values }\end{array}$ & RVPER囚P囚 & RVPFR囚P凹 & RVPER囚T囚 & RVPFR $\mathbb{T} \otimes$ \\
\hline Observer 1 & $2.07 \pm 0.70$ & $\begin{array}{l}1.38 \rrbracket 1.13 \rrbracket \\
1.79 \rrbracket\end{array}$ & $2.19 \pm 0.79$ & $\begin{array}{l}1.65 \rrbracket 1.35 \rrbracket \\
2.00 \rrbracket\end{array}$ \\
\hline Observer 2 & $2.12 \pm 0.66$ & $\begin{array}{l}1.59 \rrbracket 1.28 \rrbracket \\
1.98 \rrbracket\end{array}$ & $2.22 \pm 0.76$ & $\begin{array}{l}1.77 \rrbracket 1.29 \rrbracket \\
2.15 \rrbracket\end{array}$ \\
\hline Correlation coefficient $(95 \% \mathrm{Cl})$ & $\begin{array}{l}0.838 \rrbracket 0.757 \rrbracket \\
0.894 \rrbracket\end{array}$ & $\begin{array}{l}0.698 \rrbracket 0.507 \rrbracket \\
0.814 \rrbracket\end{array}$ & $\begin{array}{l}0.860 \rrbracket 0.789 \rrbracket \\
0.909 \rrbracket\end{array}$ & $\begin{array}{l}0.857 \rrbracket 0.780 \rrbracket \\
0.909 \rrbracket\end{array}$ \\
\hline$P$ value & $\varangle 0.001$ & $\nabla 0.001$ & 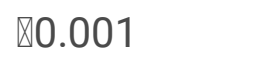 & $\nabla 0.001$ \\
\hline Difference mean & 0.06 & 0.19 & 0.03 & 0.06 \\
\hline Standard deviation & 0.39 & 0.4 & 0.41 & 0.39 \\
\hline $\begin{array}{l}\text { Upper limit of } 95 \% \text { confidence } \\
\text { interval }\end{array}$ & 0.8244 & 0.974 & 0.8336 & 0.8244 \\
\hline $\begin{array}{l}\text { Lower limit of } 95 \% \text { confidence } \\
\text { interval }\end{array}$ & -0.7044 & -0.594 & -0.7736 & -0.7044 \\
\hline Coefficient of variation (\%) & 18.6 & 25.3 & 18.6 & 21.7 \\
\hline
\end{tabular}

\section{Figures}




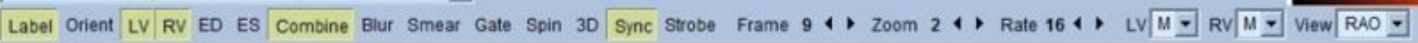

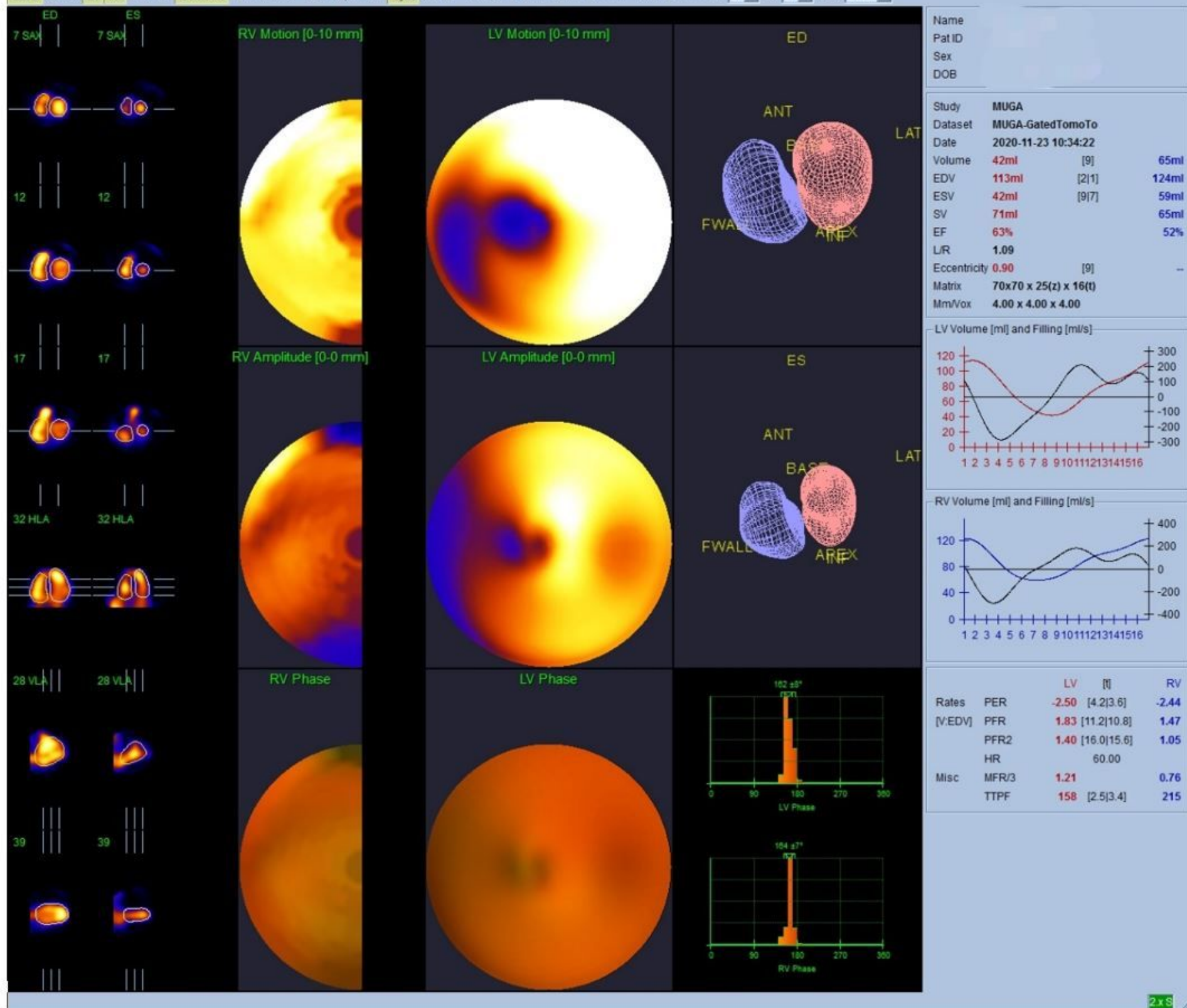

Figure 1

CZT-SPECT tomographic image and parameters calculated by Cedars-Sinai G-BPGs 
LVEF: C-SPECT vs CZT-SPECT

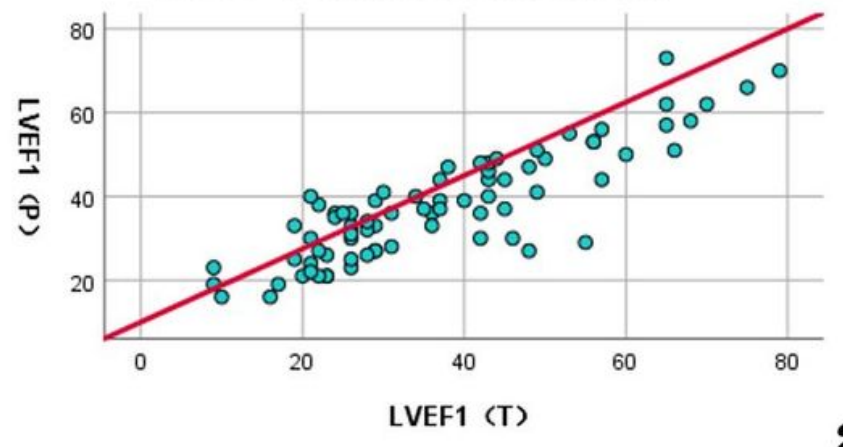

a

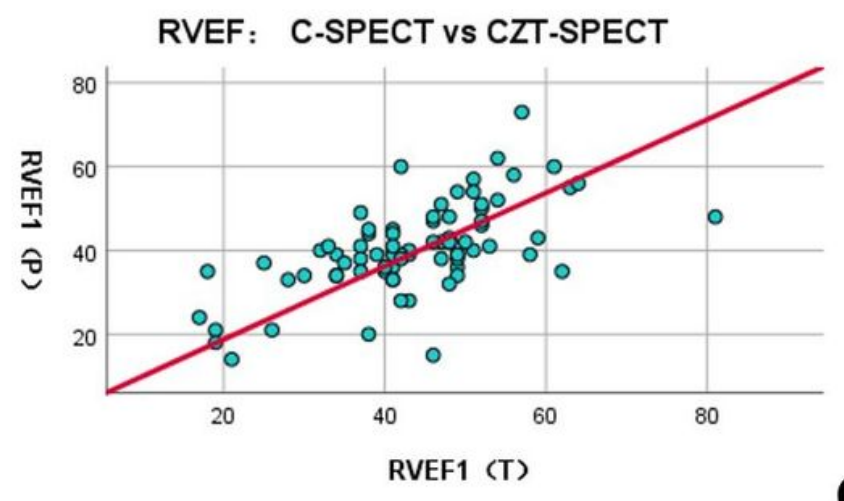

LVEF: C-SPECT vS CZT-SPECT
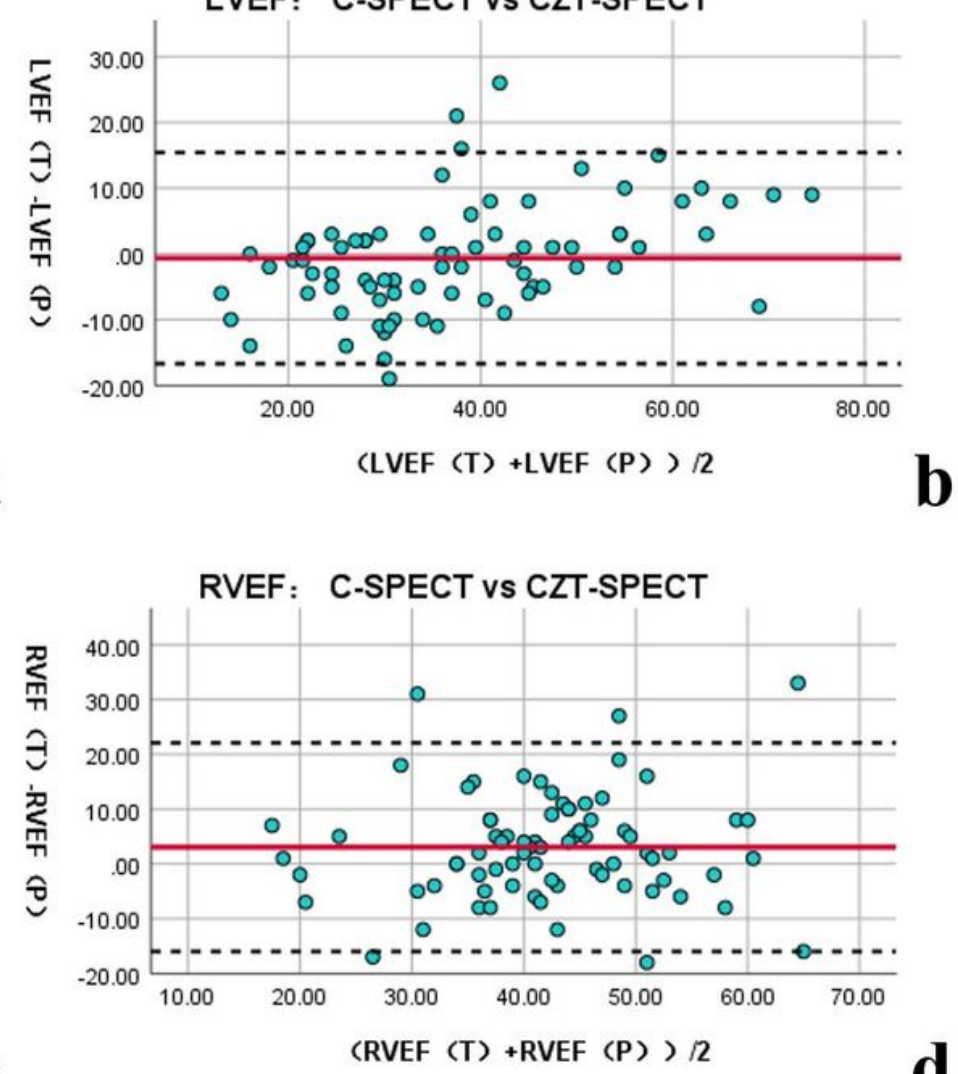

C

Figure 2

Scatter diagram of LVEF and RVEF between CZT-SPECT and C-SPECT (a) and (c) were scatter diagrams of correlation analysis of LVEF and RVEF in C-SPECT planar imaging and CZT-SPECT tomographic imaging, respectively. (b) and (d) were their Bland-Altman consistency analysis diagrams. 


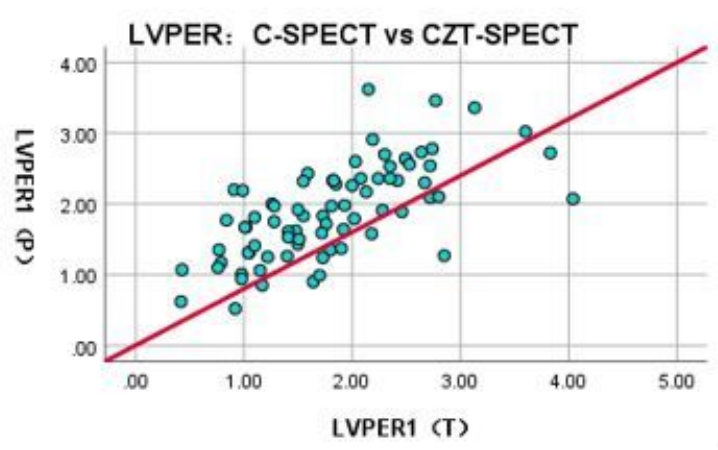

a
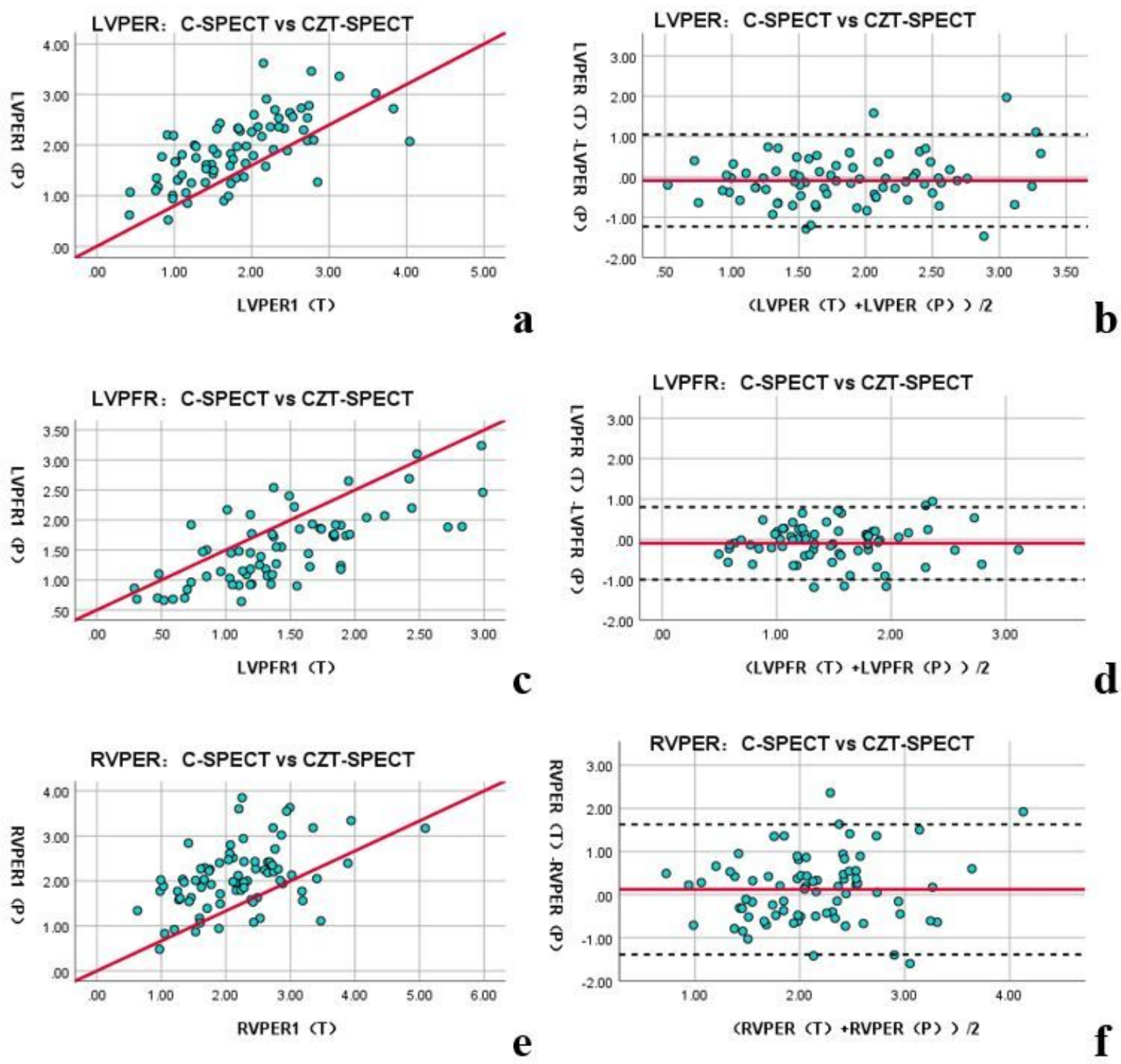

RVPFR: C-SPECT vs CZT-SPECT

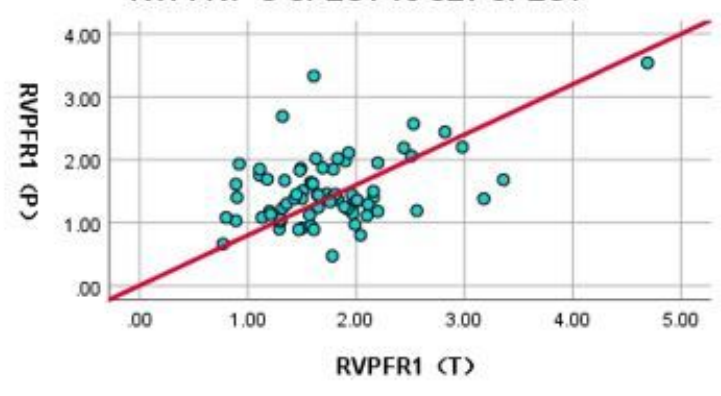

g

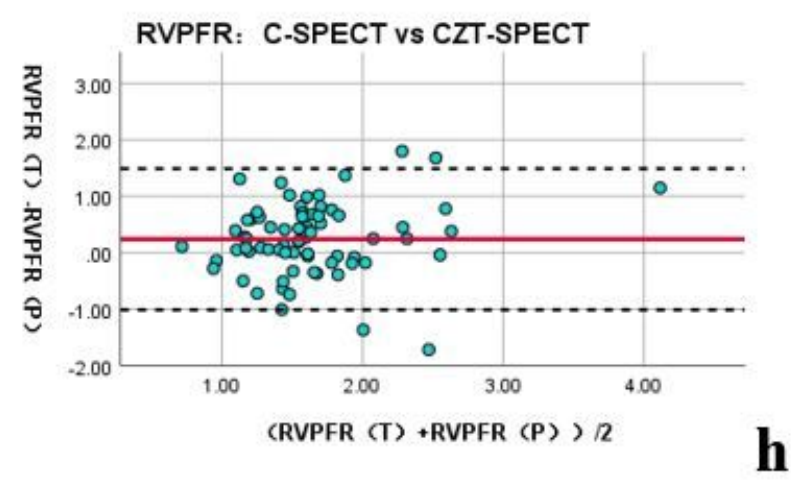

\section{Figure 3}

Scatter diagram of LVPER, LVPFR, RVPER and RVPFR between CZT-SPECT and C-SPECT (a), (c), (e) and (g) were scatter diagrams of correlation analysis of the above four functional parameters in C-SPECT planar imaging and CZT-SPECT tomographic imaging, respectively. (b), (d), (f) and (h) were their BlandAltman consistency analysis diagrams. 

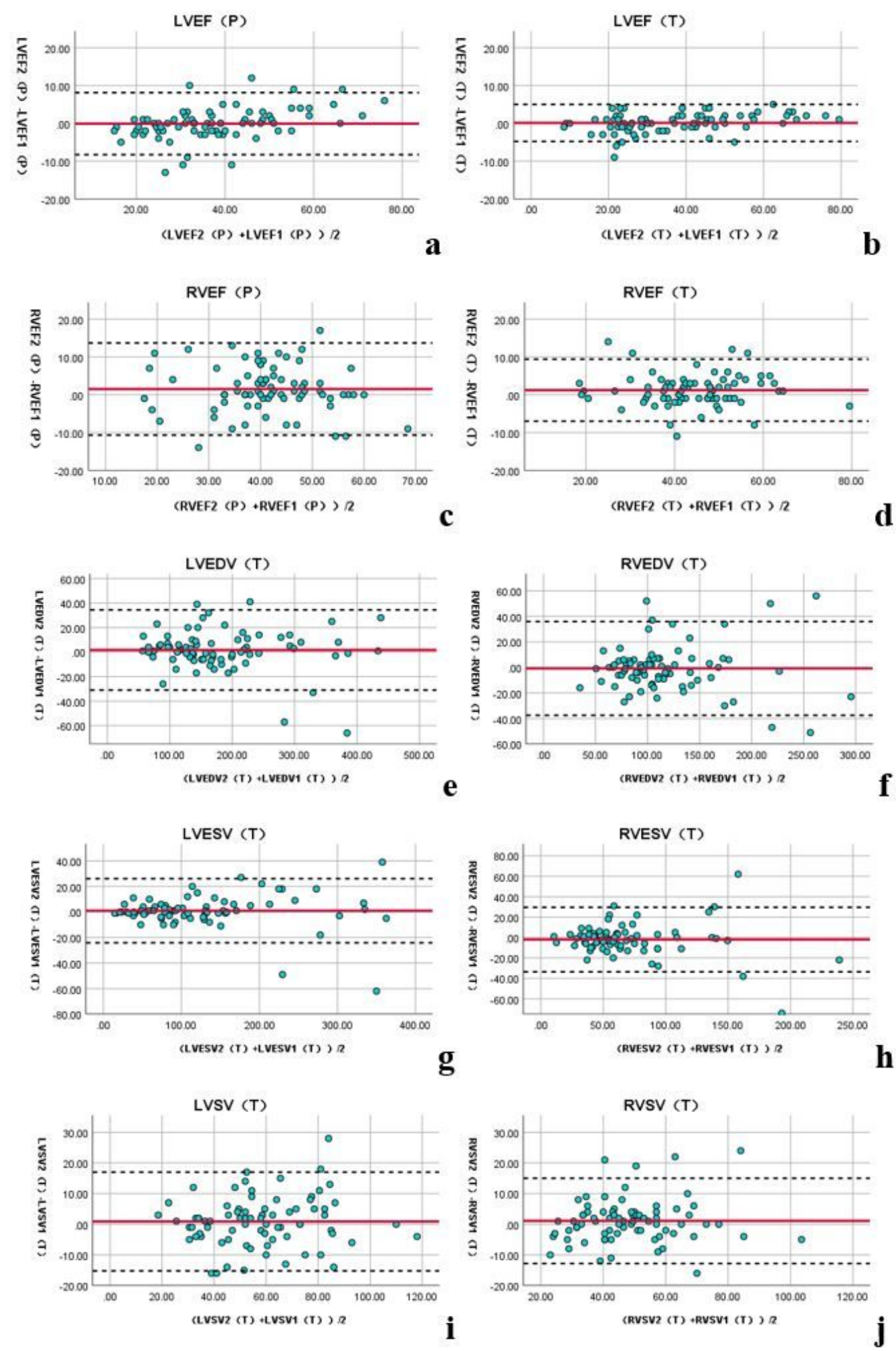

\section{Figure 4}

Bland-Altman analysis diagram of measurement repeatability of each parameter (a) and (c) are LVEF and RVEF repeatability analysis obtained by C-SPECT, while $(b),(d)$ and $(e \sim j)$ were left and right ventricular parameters repeatability analysis obtained by CZT-SPECT. 
LVPER (P)

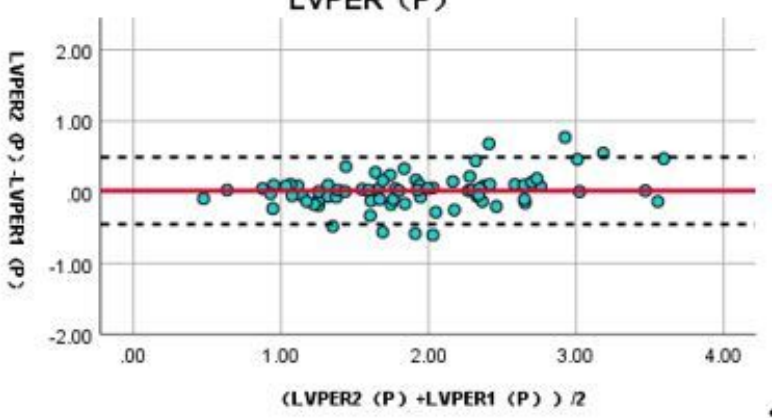

a

LVPER (T)
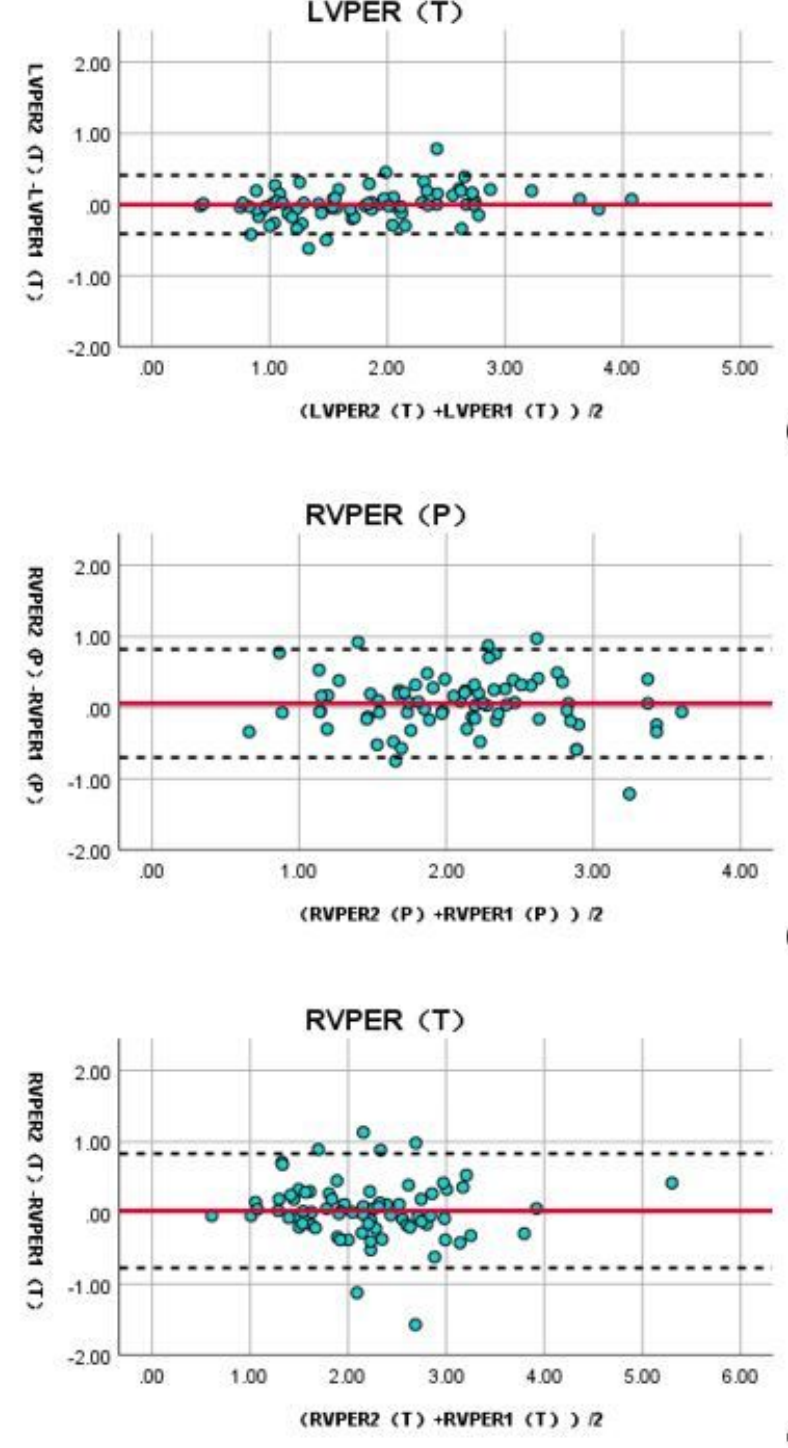
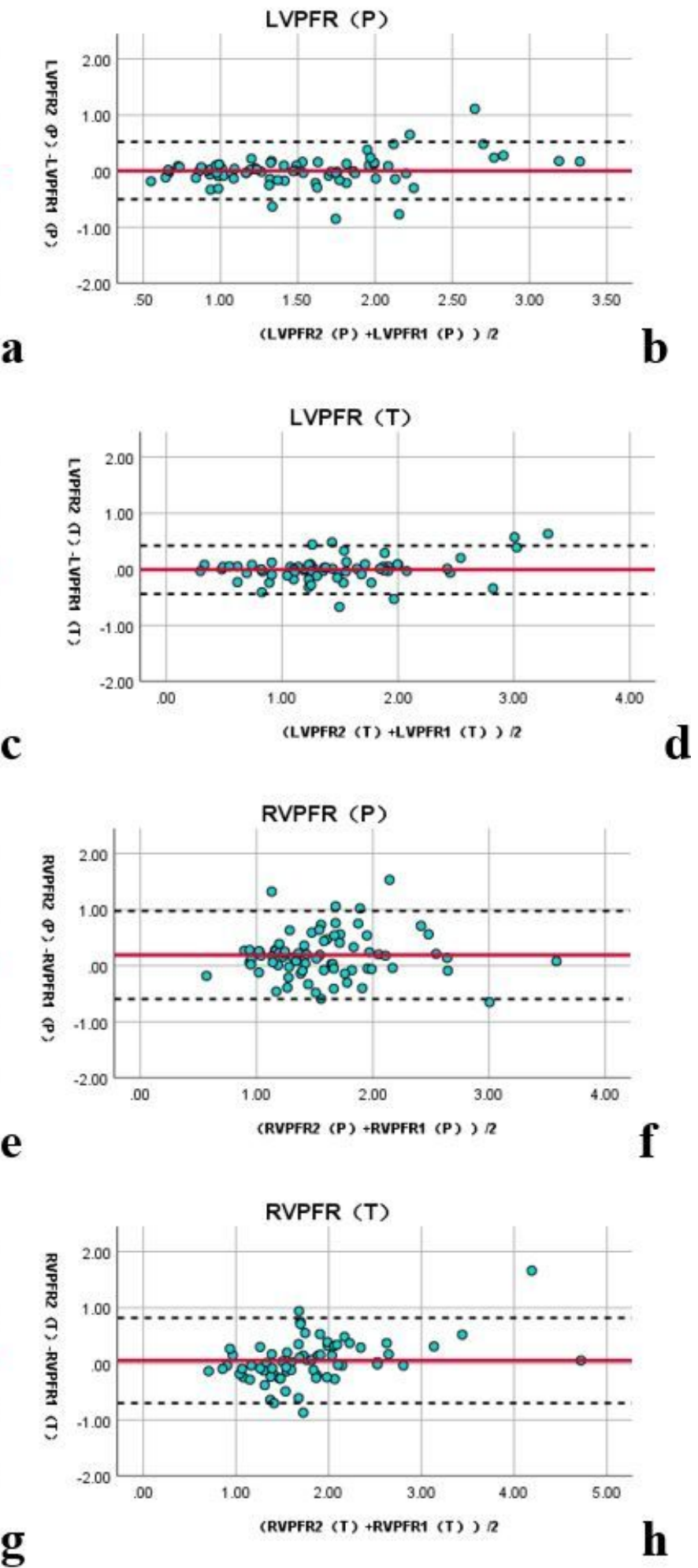

\section{Figure 5}

Bland-Altman analysis diagram of measurement repeatability of each parameter (a), (b), (e) and (f) were the repeatability analysis of LVPER, LVPFR, RVPER and RVPFR obtained by C-SPECT, while (c), (d), (g) and $(\mathrm{h})$ were the repeatability analysis of left and right ventricular parameters obtained by CZT-SPECT. 